\title{
An Insight to Harmonic Suppression Techniques with Power Filters in Power Electronics
}

\author{
Shamala N \\ Asst. Professor \\ Dept of Electrical and Electronics Engg. \\ Vidya Vikas Institute of Engineering and \\ Technology Mysuru, India
}

\author{
C. Lakshminarayana, Ph.D \\ Professor \\ Dept. of Electrical and Electronics Engg. \\ BMSCE, Bangalore, India
}

\begin{abstract}
With the advancement of IT, various high as well as low powered electronics and electrical devices have penetrated in the commercial and domestic markets. Usages of such types of electronics system are found to give rise occasionally to harmonics owing to non-linear loads. From more than a decade, there are sets of effective research contribution towards introducing a technique for suppression such harmonics using filters. However, till date there is no evidence of any standard model or framework or any landmark ideas that has solved the issue of harmonic suppression in totality. Thus, the intention of this manuscript is to discuss harmonics with respect to active power filters where the prominent focus is laid down to understand the effectiveness of priorly introduced techniques. The study presents a state-of-art review of techniques of harmonic suppression with an aid of the research gap.
\end{abstract}

\section{Keywords}

Active Power Filter, Harmonic, Passive Power Filter, Power Quality

\section{INTRODUCTION}

With the increasing adoption of the modern electrical appliance, the area of power electronics, as well as power distribution, encounters a significant challenging factor. Owing to the usage of power components like diode bridge, DC capacitors, it is extremely feasible that such devices can devour currently to the highest point of the main source voltage in interface circuits. It is known that electrical devices mainly draw non-sinusoidal currents irrespective of the applied voltage being sinusoidal [1] Outstanding to non-appropriate features of the source of voltage, voltage distortion surfaces up in electrical devices due to harmonics. In the present era, the consumers heavily uses cycloconverters, rectifier, arc furnaces, variable speed drives, asymmetrical loads that can significant produce maximized disturbances in the existing as well as in upcoming power supply system [2]. Presence of harmonics are always detrimental to power system that results in irreversible failure of the electrical components sometimes apart from frequently known heating issues in it. Typically, it humiliates the power quality system resulting in spikes, sags, swell, transients, etc. [3]. The sources of origination of harmonics are from the adjustable frequency drives as well as non-sinusoidal loads especially in the presence of ACto-DC adaptation. There are two types of mechanisms for electrical devices that generates harmonics e.g. i) static power converters e.g. DC drives, Uninterrupted power supply, adjustable frequency organizers, and ii) internal power supply e.g. copier, computer, electronic ballast etc. It was also seen that an Adjustable Frequency Controller have a converter (where DC power is converted from AC) as well as an inverter. However, both converter and inverter comprises of non-linear devices in their design of circuits. It, for this reason, generates harmonics on both input and output lines termed as line and load side harmonics. Line-side harmonics are said to be caused by converters while load-side harmonics are caused from inverters although they are separated from each other. Hence, the load-side harmonics only affect the electrical component controlled by Adjustable Frequency Controller, because line-side harmonics drastically affect the entire electrical and power system. In order to mitigate the adverse effect of harmonics in power system, acceptance of inductive reactors, active filter, passive filters, phase-shifting transformers, etc. are increasingly considered. It was also seen that there is a frequent adoption of three-four phase wire systems in the majority of the commercial applications for power distribution. In the presence of imprecisely distributed loads as well as uncompensated loads, it is highly possible that such electrical system will undergo unnecessary damage owing to non-linear loads. Hence, voltage-source is the most frequently adopted consideration compared to the current source for designing the parallel active filters owing to its potential advantages. For better power quality, maximized level of voltages over DC bus is highly preferred and can be accomplished by using a multi-level inverter. The reference current for the filter node needs to cater up conditions for eliminating harmonics, correcting power factors, voltage regulation, and compensating load unbalance. The control strategy of voltage is a concurrent goal encountered to compensate the power factor owing to the presence of reactive currents. Hence, there are multiple attributes that need to be investigated precisely to improve power quality factor.

This paper, therefore, investigates various techniques for harmonic compression in the past decade and extracts a significant research gap. In Section 2 describes the fundamentals of harmonics filter followed by Section 3 highlighting about the active power filters. Section 4 discusses recently existing review papers. Section 5 discusses some of the prominent techniques used by researchers to suppress harmonics with an assist of methods, outcomes, experimental environments. Section 6 discusses the research gap and finally Section 7 makes some concluding remakes.

\section{HARMONIC FILTERS}

With the modernization of modern power electronics, different types of system consume different types of loads. Typically, with the employ of applications like computers, laptops, and various other embedded system, the endurance of usage of non-linear electric loads are high on the use. Fig.1 exhibits the generation of multiple orders of harmonics with respect to amplitude and time. Hence, harmonic occurs owing to non-linear electric loads and effect the operational current and voltage. In order to mitigate the adverse effects of harmonics, the engineers design power filter that can minimize the side effects of harmonics on the power system and targets to enhance the power quality. Therefore, harmonics filters are developed to minimize problematic harmonics to a specific value to resist harmonic amplification. 


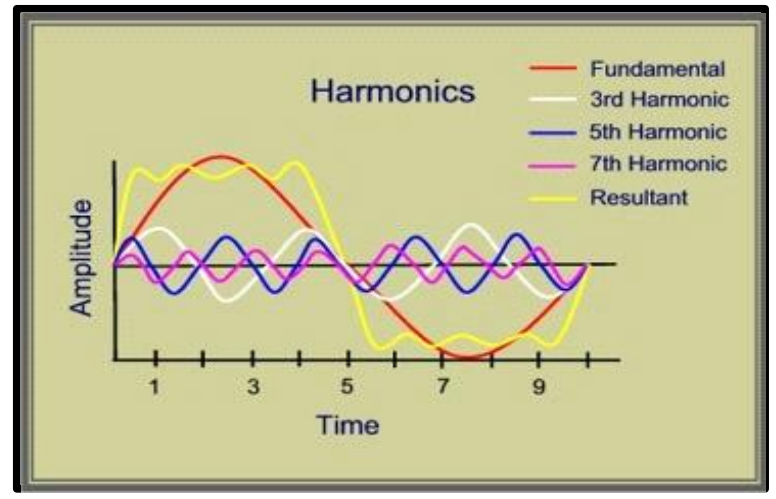

Fig. 1: Harmonics Fundamentals [4]

\subsection{Causes of Harmonics in Power System}

At present time, the consumers use various type of application that are based on power converters e.g. variable speed drives, rectifiers, inverters, soft-starter, switch-mode energy supply, uninterrupted power supply, etc. Such types of frequently used devices in power electronics adopts switching mechanism using semi-conductor precisely to control speed, output, torque, as well as energy efficiency on the electrical system. Compared to linear loads (e.g. capacitors, inductors, and resistors), such devices consumes continuous current from the source of supply. However, non-linear loads can consume short and rapid burst of current from the supply source. Another cause of harmonic is when the system apply a sinusoidal voltage to linear device, and the current factor is found to sinusoidal too. When a system applies sinusoidal voltage to any non-linear device, it was seen that the output will be non-sinusoidal thereby giving rise to harmonics. Therefore, the yielding non-sinusoidal waves that are disrupted by the presence of harmonics can be studied from various degrees of harmonics ranging from fundamental (1st harmonic) to the larger order (Fig.1). The significant causes of generation of harmonics are basically the frequency and amplitude of harmonic current generated, quantity as well as type of non-linear load integrated in power system, and strength of power supply as well as system impedance factor. Hence, these are some of the significant causes of harmonics that adverse effect power system.

\subsection{Effect of Harmonics on Power System}

Harmonics always have an adverse effect on power system that can be discussed in multiple manners. The first physically sensed issues of harmonics are overheating of the power system that is followed by breakdown of insulation. Owing to overheating of electrical equipments (switchgear, transformer, conductors, etc.), it undergo irreversible operational failure. Another soft target of harmonics is a capacitor bank, which are normally adopted for correcting the power factor as well as used for controlling voltage. It occurs owing to the low impedance at maximized level of harmonics. Some of the other effects of harmonics are malfunctioning of PLL circuits, loss of motor winding, perturbing torque on the motor shaft, communication interference, blown fuse, and occasional tripping of circuit breaker.

\subsection{Categories of Harmonic Filters}

Basically, harmonic filters aims to reduce the effect of harmonics and thereby maximize the power quality. They are signified into 4 categories as briefly discussed below:

\subsubsection{Passive Harmonic Filter}

Such types of harmonic filters are designed from linear load systems like capacitors, resistors, and inductors. In conventional power system, passive harmonic filter is designed from capacitors and inductors mainly and are adjusted for operating on a particular frequency depending upon the requirement of the user. Such system also adopts multiple filters for multiple frequencies that are required to be eliminated. Hence, in normal usage, passive harmonic filters can be used to reduce the number of electrical components. However, it should be known that passive filters have some drawbacks too. A passive filter is one of the cost effective filters that are widely adopted in the majority of the voltage levels. Incorrect usage of passive filters leads to the breakdown of the entire filters.

\subsubsection{Damped Harmonic Filters}

It was seen that passive filters are adopted to adjust to consuming a fundamental harmonics although it will invariably affect the magnitudes of other harmonics as well in the electrical networks. Hence, damped harmonic filters can be used to implicate better resistance into the filter circuits for furnishing a damped response across a wider frequency range. The damped filters are also highly adjustable to get configured into multiple degrees of harmonics for mitigating fundamental losses of frequency

\subsubsection{Active Harmonic Filters}

This is one of the widely used power harmonic filters and is a constant focus of the research community. The job of active filters are to eliminate the unnecessary harmonic currents from the electrical network by producing harmonic current in antiphase with the targeted harmonics that is required to be suppressed. Active filters offers better flexibility to mitigate harmonics compared to conventional passive filters in order to eliminate lower order harmonics.

\subsubsection{Hybrid Harmonic Filters}

Although there are various advantages of both passive and active filters, there are some significant pitfalls too. For an example, although passive filter is cost effective, but sometimes it evolves up with a situation that produce reactive power causing undesirable effects to multiple harmonics order. Similarly, Active filters can optimize their residual output to filter out the single maximized harmonics in the network, but it cannot deal with $5^{\text {th }}$ harmonics which is one of the most significant harmonics on distribution network. Hence, hybrid harmonic filters are designed by amalgamating the potential beneficial factors of both passive and active harmonic filters, where the passive filter can be used for minimizing lower order harmonics $\left(5^{\text {th }}\right.$ and $\left.7^{\text {th }}\right)$, while active filter can be used for higher order harmonics. Hence, hybrid filters ensure better size and cost efficiency in the area of harmonic filters.

\section{ACTIVE POWER FILTER}

In the area of power filter, there are various types of power filters as seen in the prior section. However, adoption of active power filter is quite high as seen in the topic of research-based investigation for minimizing harmonic distortion. Active Power Filter is designed for the purpose of optimizing the modern technologies of power electronics for generating particular components of current that can eliminate adverse harmonic current caused due to non-linear loads. Investigation shows that active power filter is better compared to conventional passive power filter in following manner e.g. i) active power filter can eliminate harmonics generated from both reactive current as well as supply currents, ii) Active power filter doesn't generate harmful resonance like passive power filter in any power distribution networks, iii) active power filter is free from any dependency on power distribution system properties. However, owing to the novelty of technologies associated with active power filter, still investigation is an on-going process in power 
electronics. Fig. 2 highlights the actual components used in any standard active power filters and their respective operation.

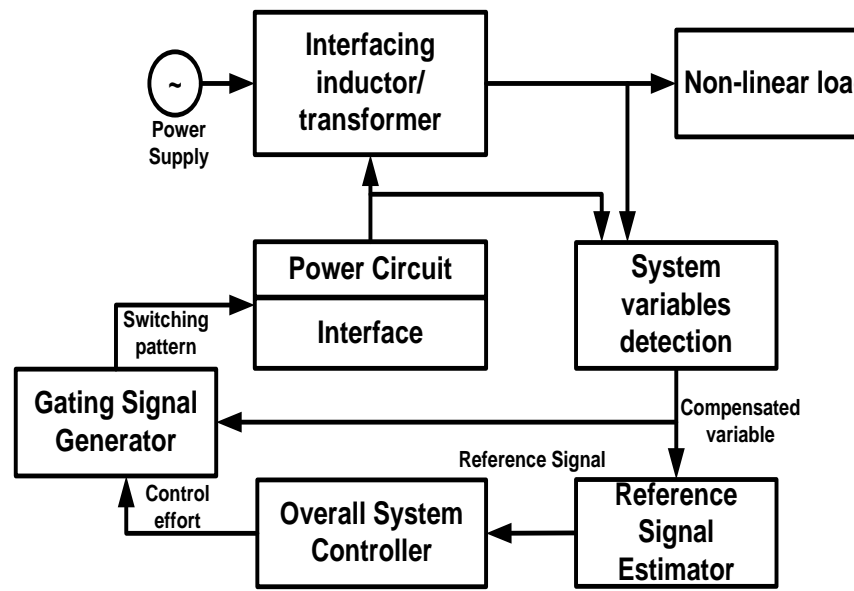

Fig. 2: Active Power Filter Design

Fig.2 shows that the overall system controller is driven by compensation reference signal that furnishes the cumulative control for the gating signal generator. The output signal generated from the gating signal generator actually controls the power circuit using an appropriate interface. Ultimately, the circuit design shown in Fig. 3 can be of any form of connectivity (series, parallel, series-parallel, etc) based on type of interfacing transformer or inductor to be used. However, active power filter has higher dependency on faster switching mechanism for higher current that can be considered as compensator for harmonics. The entire operation on active power filter is carried out by i) signal conditioning, ii) extraction of compensating signals, and iii) generation of gating signals.

The operation carried out in signal conditioning allows the filter to identify and sense the harmonics in the power distribution network. The reference signal is the prime component that guarantees the precise functionality of active power filter to be processed by controller. The current and voltage factors in the electrical system are identified by using the current transformer, potential transformers, and isolated amplifiers. The voltage factors to be identified in this process will be AC source voltage, DC bus voltage as well as voltage across interfacing transformer. After this, the time-domain or frequency-domain is adopted for evaluating feedbacks, reference signals. Active power filters are again classified into three types as discussed below:

\subsection{Series Filters}

The series filters generate pulse width modulated voltage waveforms that are either subtracted or added on an instantaneous basis from/to the supply voltage for ensuring a pure sinusoidal voltage waveform over the load. A typical series active power filter design is shown in Fig.3. The system uses voltage-fed inverter for inverter configuration without any current-control loops. However, such types of filters are least adopted in commercial practices as compared to parallel active power filters. The prime reason behind this is issues of series circuits for handling maximized load current that maximizes the rating of their currents significantly as compared to parallel active power filters. Series filters are preferred for reducing harmonics of voltage-waveform for ensuring proper equilibrium of three-phase voltages. It can be also said that series filters can enhance the power quality for the benefit of load and furnishes load with an appropriate sinusoidal waveform that are critically required for voltage-sensitive devices.

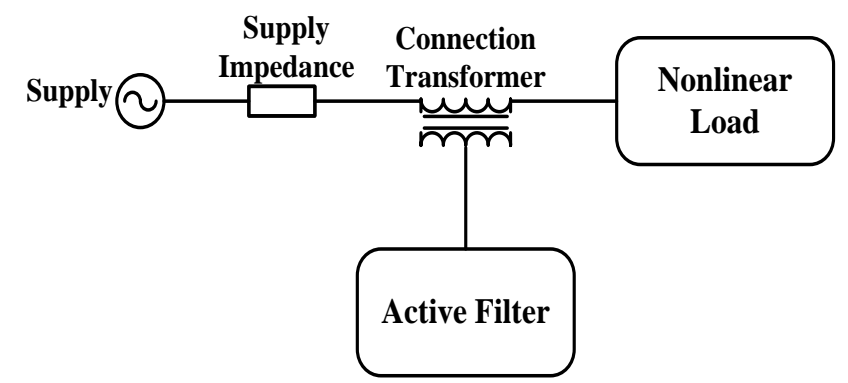

Fig. 3: Series Active Power Filters

\subsection{Shunt Filters}

This type of the filters is widely adopted for eliminating harmonics fed to the supply. The standard circuit design of series active power filter is shown in Fig.4. Shunt active power filters can be also used for compensating reactive power and ensuring proper equilibrium of three-phase currents. Shunt active power filter have potential advantages over passive, active power filter. Such filter is capable of carrying specifically compensating currently along with the small quantity of active fundamental currents that are supplied to compensate for the system losses. It is also feasible for integrating various filters in parallel for maximized currents for better power ratings.

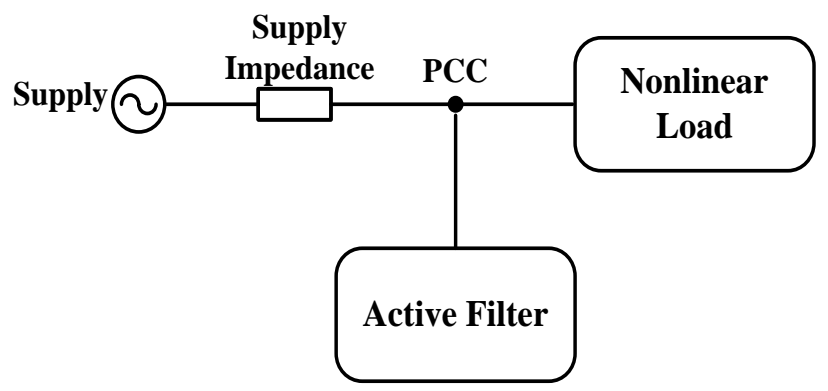

Fig. 4: Shunt Active Power Filters

\subsection{Hybrid Filters}

Although active power filters have potential advantages, they bear a limitation too, that are usually overcome by adopting the design principles of hybrid active power filter. Hybrid active power filters is designed by integrating both fundamental active power filter and passive power filter and bears the potential beneficial characteristics of both active power filter and passive power filter for furnishing enhanced power quality and costeffective power supply. A standard circuit design of hybrid power filter is highlighted in Fig.5

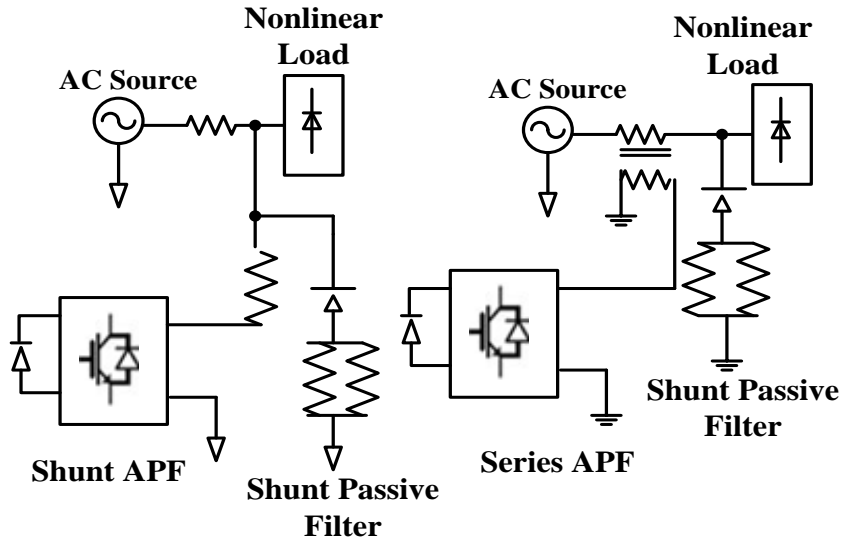

(a) Shunt APF+Shunt PF

(b) Series APF+Shunt PF 
The prime objective of hybrid power filter is to perform parallel minimization of interference caused due to electromagnetic and noise due to the switching mechanism. The primary goal of using hybrid active power filter is to enhance the high-order harmonics thereby ensuring cost effective solution for eliminating low order harmonics.

\section{EXISTING REVIEW OF ACTIVE POWER FILTER}

The investigation towards exploring the superior active power filter is not a new arena in the research community. It was found that various researchers in most recent times have also performed reviewing various techniques of active power filter for harmonic suppression. The initial review towards the active power filter was published by Won [5] where the authors have discussed various issues of harmonics with respect to the nature, impact, sources, and standards of harmonics. Chaturvedi et al. [6] have also reviewed some of the techniques of active power filter with focus on non-linear loads. Most recently in 2014, the frequency of publications for review papers was seen to be quite high. Jacob et al. [7] have discussed the theoretical understanding of power system harmonics with illustration of active power filter and its operations. The author have also discussed the classification of active power filter into three types i) Shunt, ii) Series, and iii) Hybrid. Raouf et al. [8] have investigated techniques towards improving power quality with an aid of active power filters and their respective controlling techniques. Ahmad and Jaglan [9] have discussed the issues pertaining to harmonics and the techniques to eliminate them. Choudhary and Gaur [10] have discussed the control strategies towards active power filters exiting in the most recent times. The controlling techniques discussed by the author were signaling conditioning stage, derivation of compensation signal stage, and generation of gating signals. Apart from this authors have briefly hinted that in the existing system, various techniques frequently adopted for minimizing harmonics were neural network, wavelets, hysteresis control, fuzzy logic, etc. Arthy and Marimuthu [11] have reviewed the control strategies for total harmonic distortion and theoretically discussed p-q theory, SRF (synchronous reference frame) Theory, SDM (synchronous detection method) theory, sliding mode controller, Pulse width modulation, and DSP-FPGA based schemes, etc. Table 1. Summarizes existing reviews on active power filter.

Table. 1: Summary of Existing Reviews on Active Power Filters

\begin{tabular}{|c|c|c|c|c|}
\hline Index & Year & $\begin{array}{c}\text { Discussion } \\
\text { of theory }\end{array}$ & $\begin{array}{c}\text { Discussion } \\
\text { on } \\
\text { research } \\
\text { papers }\end{array}$ & $\begin{array}{c}\text { Discussion } \\
\text { on } \\
\text { Research } \\
\text { gap }\end{array}$ \\
\hline
\end{tabular}

\begin{tabular}{|c|c|c|c|c|}
\hline$[5]$ & 2009 & $\sqrt{ }$ & $X$ & $X$ \\
\hline$[7]$ & 2014 & $\sqrt{ }$ & $X$ & $X$ \\
\hline$[6]$ & 2012 & $\sqrt{ }$ & $X$ & $X$ \\
\hline$[8]$ & 2014 & $\sqrt{ }$ & $\sqrt{ }$ & $X$ \\
\hline$[9]$ & 2014 & $\sqrt{ }$ & $X$ & $X$ \\
\hline$[10]$ & 2014 & $\sqrt{ }$ & $X$ & $X$ \\
\hline$[11]$ & 2014 & $\sqrt{ }$ & $\sqrt{ }$ \\
\hline
\end{tabular}

\section{EXISTING TECHNIQUES OF ACTIVE POWER FILTER}

Afonso et al. [12] have developed a design of shunt active power filter that permits correction of dynamic power factor and effectively compensates both zero-sequence and harmonics. The design principle was mainly based on $\mathrm{p}-\mathrm{q}$ theory. The simulation was performed in Simulink to evaluate shunt active filter. Study on adoption of shunt active power filter was also carried out by Kumar [13]. Designed on Simulink, the outcome of the study have exhibited better performance of controlled design where total harmonic current was reduced by $5 \%$ of the harmonics limit. Martinek et al. [14] have also adopted shunt active power filter for enhancing the power quality. The author has set the novelty in their work by incorporating Artificial Intelligence method. Implemented in Simulink, the outcome of the study was evaluated using a reference voltage process with respect to current, percentile of fundamentals with order of harmonics, and current with time. The outcome also exhibited that total harmonic distortion is enhanced by using ANFIS. Similar direction of the study was also performed by Poorvi et al. [15] and Daniel et al. [16]. However, Daniel et al. [16] have used hybrid active filter using reduced switch topology (B4) to ensure better cost minimization and bridge losses. Study towards enhancing power quality was witnessed in the research paper of Martins [17] However, it was found that the most effective work studied till date is the design of active power filter proposed by Moran et al. [18] The author have considered reactive power for designing the power circuit and control circuit, where the experiment were carried out on 5-kVA prototype using IGBT switches. The observation was done on steady state and transient operating condition. The outcome of the study has exhibited an increase in inverter voltage gain and minimization of ripples. Various experiments were seen towards series active power. Owing to certain beneficial factors (e.g. current compensation caused by non-linear loads, high impedance, correction of voltage imbalance), Moran et al. [19] have adopted series active power filter.

Table. 2: Summary of Existing Implementations on Active Power Filters

\begin{tabular}{|c|c|c|c|c|c|}
\hline$\#$ & Year & Method & Real-Time & Simulated & Benchmarked \\
\hline$[12]$ & 2000 & PQ-theory & $\mathrm{X}$ & $\mathrm{V}$ \\
\hline$[17]$ & 2003 & $\begin{array}{c}\text { Dynamic compensation of a three-phase } \\
\text { diode rectifier }\end{array}$ & $\mathrm{X}$ & $\sqrt{\text { (SABER) }}$ & $\mathrm{X}$ \\
\hline$[18]$ & 1995 & PWM, Fixed Switching Frequency & $\begin{array}{c}\sqrt{ }(5 \mathrm{kVA} \text { prototype } \\
\text { using IGBT switch) } \\
\sqrt{(5 \mathrm{kVA} \text { prototype }}\end{array}$ & $\mathrm{X}$ & $\mathrm{X}$ \\
\hline$[19]$ & 2000 & Series Active Power Filter & $\mathrm{X}$ & $\mathrm{X}$ \\
\hline$[20]$ & 2010 & Model for voltage sags and swells & $\mathrm{X}$ & $\sqrt{\text { (Simulink/ TINA }}$ & $\mathrm{X}$ \\
\hline
\end{tabular}




\begin{tabular}{|c|c|c|c|c|c|}
\hline & & mitigation & & PRO) & \\
\hline$[21]$ & 2011 & Shunt Active Power Filter & $\mathrm{X}$ & $\sqrt{ }$ (PSpice) & $\mathrm{X}$ \\
\hline [13] & 2007 & $\begin{array}{l}\text { Fuzzy Controller-Shunt Active Power } \\
\text { Filter }\end{array}$ & $\mathrm{X}$ & $\sqrt{(\text { Simulink })}$ & $\mathrm{X}$ \\
\hline$[22]$ & 2012 & Shunt Active Power Filter & $\mathrm{X}$ & $\sqrt{ }($ Simulink $)$ & $\mathrm{X}$ \\
\hline$[23]$ & 2010 & Two-level hysteresis controller & $\begin{array}{l}\sqrt{\text { (IGBT switch }+ \text { Texas }} \\
\text { Instruments } \\
\text { TMS320F2812 Digital } \\
\text { Signal Processor) }\end{array}$ & $\mathrm{X}$ & $\mathrm{X}$ \\
\hline [14] & 2013 & Shunt Active Power Filter + ANFIS & $\begin{array}{l}\sqrt{(\text { intelligent electronics }} \\
\text { device })\end{array}$ & $\sqrt{(\text { Simulink })}$ & $\mathrm{X}$ \\
\hline [15] & 2013 & Shunt Active Power Filter & $\mathrm{X}$ & $\sqrt{(\text { Simulink })}$ & $\mathrm{X}$ \\
\hline$[24]$ & 2007 & SRF Controller + PQ Theory & $\mathrm{X}$ & $\sqrt{ }($ Simulink $)$ & $\mathrm{X}$ \\
\hline$[25]$ & 2010 & Hybrid Active Power Filter & $\begin{array}{l}\sqrt{(d S P A C E ~ D S 1104 ~} \\
\text { DSP controller })\end{array}$ & $\mathrm{X}$ & $\mathrm{X}$ \\
\hline$[26]$ & 2014 & $\begin{array}{c}\text { Comparative analysis of different active } \\
\text { power filter }\end{array}$ & $\begin{array}{c}\sqrt{(\mathrm{dSPACE} \text { control }} \\
\text { board of } 750 \mathrm{GX} \\
\text { processor })\end{array}$ & $\mathrm{X}$ & $\mathrm{X}$ \\
\hline$[27]$ & 2012 & $\begin{array}{l}\text { 7-level shunt active power filter + SDM } \\
\text { circuit }\end{array}$ & $\mathrm{X}$ & $\sqrt{ }($ Simulink $)$ & $\mathrm{X}$ \\
\hline$[16]$ & 2013 & Shunt Hybrid active power filter & $\mathrm{X}$ & $\sqrt{ }($ Simulink $)$ & $\mathrm{X}$ \\
\hline$[28]$ & 2008 & Shunt Active Power Filter & 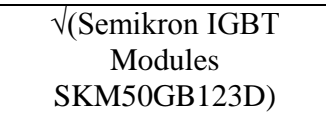 & $\mathrm{X}$ & $\mathrm{X}$ \\
\hline [29] & 2009 & Synchronous Generator & $\mathrm{X}$ & $\sqrt{ }$ & $\mathrm{X}$ \\
\hline$[30]$ & 2014 & Discrete Wavelet Transform & $\mathrm{X}$ & $\sqrt{ }$ (Simulink) & $\mathrm{X}$ \\
\hline [31] & 2014 & $\begin{array}{l}\text { Comparative analysis of different active } \\
\text { power filter }\end{array}$ & $\begin{array}{l}\sqrt{(\text { dSPACE Board- }} \\
\text { DS1104) }\end{array}$ & & $\mathrm{X}$ \\
\hline$[32]$ & 2011 & FPGA + Fuzzy Logic & $\sqrt{\text { (FPGA Board) }}$ & $\sqrt{ }$ (Simulink) & $\mathrm{X}$ \\
\hline$[33]$ & 2010 & FPGA & $\sqrt{(\text { Cyclone II-Altera })}$ & $\begin{array}{c}\sqrt{ }(\text { Simulink })+ \\
\text { Altera's Quartus II } \\
\text { design software }\end{array}$ & $\mathrm{X}$ \\
\hline$[34]$ & 2011 & FPGA + Series Filters & $\begin{array}{l}\sqrt{(T M S 320 F 2812 ~ D S P ~} \\
\text { and 3s400pq208-4- } \\
\text { SPARTAN III FPGA) }\end{array}$ & $\mathrm{X}$ & $\mathrm{X}$ \\
\hline$[35]$ & 2005 & FPGA+Newton climbing method & $\begin{array}{l}\sqrt{(\text { Altera FLEX 10K }} \\
\text { FPGA) }\end{array}$ & $\mathrm{X}$ & $\mathrm{X}$ \\
\hline [36] & 2013 & Predictive Compensation & $\begin{array}{l}\sqrt{(\text { HIOKI PQA-HiView }} \\
\text { PRO 9624-50 power } \\
\text { quality } \\
\qquad \text { Analyzer) }\end{array}$ & $\mathrm{X}$ & $\mathrm{X}$ \\
\hline$[37]$ & 2012 & $\begin{array}{l}\text { Neural Network }+ \text { Shunt Active Power } \\
\text { Filter }\end{array}$ & $\mathrm{X}$ & $\sqrt{ }($ Simulink $)$ & $\mathrm{X}$ \\
\hline$[38]$ & 2013 & PQ-Theory & $\begin{array}{l}\sqrt{(\mathrm{d} \text { Space } 1103 \text { DSP }} \\
\text { system })\end{array}$ & & $\mathrm{X}$ \\
\hline [39] & 2004 & PQ-Theory & $\mathrm{X}$ & $\sqrt{ }$ & $\mathrm{X}$ \\
\hline$[40]$ & 2014 & PQ-Theory + Shunt filter & $\mathrm{X}$ & $\sqrt{ }$ & $\mathrm{X}$ \\
\hline [41] & 2006 & PQ-Theory & $\mathrm{X}$ & $\sqrt{ }$ & $\mathrm{X}$ \\
\hline
\end{tabular}


Research on similar direction was also carried out by Hussain et al. [21], where the author have used series active power filters and performed the simulation using PSpice. Pacis et al. [20] have proposed triple frameworks for mitigating sag and swell issues in harmonics by using active power filter. The secondary aim of the study was also to correct the power factor. Implemented in Simulink, the outcome of the study shows significant correction of power factor to unity. Emphasis towards power quality enhancement was observed in the work being carried out by Ravindra et al. [22]. Brandstetter et al. [23] have adopted realtime design of DSP to control active power filter. The outcome of the study was evaluated using two-level hysteresis current on 20 $\mathrm{kHz}$ IGBT switches with maximum current 78A. Some of the studies introduced in most recent times have incorporated certain level of uniqueness. For an example-the study carried out by Salam et, al. [24] have presented a hybrid version of active power filter considering the case study of a PV array. The model has been implemented on dSPACE DSII04 DSP controller, and the outcome has been evaluated using spectrum analysis of source current on multiple scenarios. This work is the first of its kind that has attempted to integrate PV system with hybrid active power filter. However, the study was focused on high-order harmonics and adopts simpler compensation current reference.

Salmeron et al. [25] have designed a prototype of four different topologies of active power filter considering non-linear loads. Leela and Dash [26] have presented active power filter to generate seven voltage levels for minimizing the switching current ripple as well as load power factor using Simulink. Similar direction of the research is also found by the work carried out by Normanyo [27]. Adoption of shunt active power filter was also witnessed in the study proposed by Routimo [28].

Hacil et al. [29] have adopted a case study of wind energy and targeted to enhance power generation and minimize harmonics using active power filter. The outcome of the study was found to minimize harmonics by $30 \%$. Madhavi et al. [30] have adopted discrete wavelet transform as well as active power filter to ensure identification and location in time for both steady and transient state signals. Considering input voltage as 230 volts and simulated in Simulink, the outcome of the study was analyzed with respect to voltage sag and swell waveforms and the coefficient in DWT. Another unique study was proposed by Merabet et al. [31] most recently, where the author have adopted neural network to evaluate harmonics in dSPACE board. The outcome of the study was evaluated and compared with P-Q theory and diphase currents with respect to reactive power compensation, extent of harmonic compensation, and direct components needed. Simulated in Simulink model, the model considered unique values of the utility source, non-linear loads, and active power filter. The frequently used architecture for single and three-phase series active power filter is exhibited in Fig.6 and Fig.7. Prusty [32] have adopted FPGA-based approach to mitigating harmonics using active power filter using SRF theory and fuzzy logic. Adoption of FPGA-based implementation was also carried out by Selvajyothi and Janakiraman [33] using single phase inverter. Darly et al. [34] have investigated on series active power filter using FPGA for improving the quality of power. The study has presented a fully digitized hardware design scheme using Pulse Width Modulation technique. Adoption of multilevel converter for mitigating harmonics was seen the work carried out by Du [35]. The authors have carried out evaluation on 11-level converter to validate their outcomes. The study was more inclined to address voltage flickering problem. Xiao et al. [36] have investigated o shunt active power filter with split capacitor for reducing multi-repetitive errors. The outcome of the study was found to ensure total harmonic distortion minimization up to $4.35 \%$ and successfully caters up IEEE-519 standards.
Gowtami et al. [37] have designed controlled using neural network for enhancing the power quality using shunt active power filter. Studies towards adoption of PQ-theory was also seen in the work of Bitoleanu and Popescu [38], Watanabe et al. [39], Jeevananthan [40], and Pavlanin et al. [41]. Various authors have also used SABER simulation tool [42] to design active power filter.

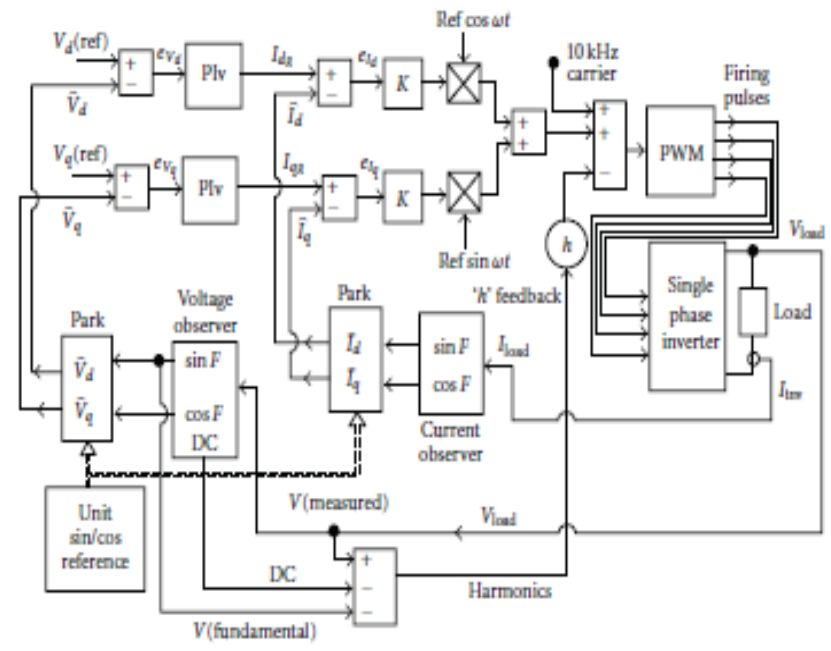

Fig.6 Single Phase Series harmonic compensation [33]

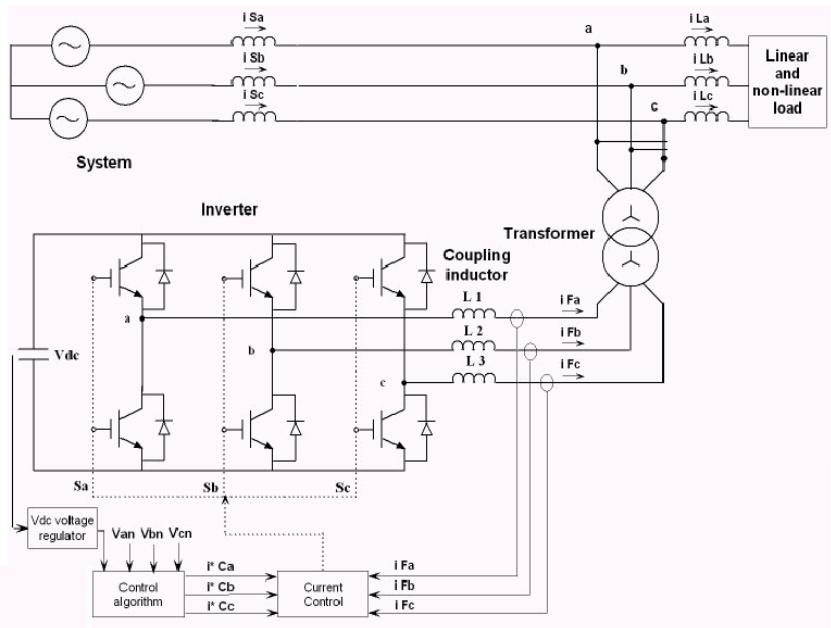

Fig. 7 Three-phase Series Active Power Filter [34]

Interestingly, the authors have used conventional Newton climbing method [43] for higher order elimination of harmonics. It was also seen that PQ-theory is also frequently adopted in harmonic mitigation study. Couto et al. [44] have adopted PQtheory to design a controller using shunt active power filter. Table 2 summarizes the cumulative techniques introduced by various authors to enhancing the power quality factors ranging from publication year 1995-2014. The tabulated data basically highlights the methods of experiments and their adopted environment primarily focusing on their techniques being adopted. The next section will discuss about the research gap that has been identified after reviewing the research papers discussed in this manuscript.

\section{RESEARCH GAP}

From the discussion in all the prior sections, it was seen that evolution of harmonics and its significance in the research community is not new. The researchers from the past decade have been attempting to showcase various techniques to eliminate 
harmonics for the purpose of enhancing power quality. In order to do so, it was seen that adoption of active power filter is quite higher even compared to hybrid active power filters for suppressing harmonics in the electrical system. There are large scales of experiments being performed both real-time as well as in the simulation environment to validate the outcomes accomplished by the researchers. Enough Studies have been done on Active Power Filter towards harmonic compensation during 1995-2014. Hence, following are the research gaps that have been explored after in-depth investigation of the outcomes highlighted in the studied prior techniques.

\subsection{Ineffective Review Papers}

Before starting the write-up of the proposed review manuscript, it was attempted to see if there are some existing review papers for harmonic elimination. It was found that there are more than 47 papers from the year 2002 till date that have already reviewed various techniques of harmonic suppression in power electronics. However, in the present paper, we choose to discuss only the most recent review papers on active power filters to narrow down our investigational focus (Section 4). It was found that all the existing review papers on active power filters, as well as harmonic suppression, are more or less the replica copy of each other. The review paper discussed by Jacob et al. [7], Chaturvedi et al [6], Raouf et al. [8], Choudhary and Gaur [10] have only focused on theoretical operations of active power filter without any significant discussions on existing research contribution. We strongly believe that an objective of a review paper is to discuss the prominent techniques discussed by prior researchers to date to understand the most effective techniques in this field of study. However, if someone reads all the existing review papers in this topic, the readers will only come to know about theoretical idea of domain and not the technical idea about the methods being adopted by researcher, their outcomes, their tools, etc. Hence, the proper decision cannot be made by the reader after reading the existing survey paper about the most effective techniques.

\subsection{No Benchmarked Works}

In the area of research, the reliability of the introduced model of researcher is determined by the performing comparative analysis of their outcomes with the most standards outcomes (or model) of other researchers. However, if the performance comparative analysis is missing in any research manuscript focusing on implementation model on active power filter, it should not necessary mean that model is not effective, but if the outcomes are compared with similar test bed and significant performance parameters, it become easy for the readers (or new researcher) to understand the most effective techniques. A table 2 showcases that till date; very few studies were found to be benchmarked. To discuss a few e.g. Afonso et al. [12], Martins [17], Moran et al. [18], Pacis et al. [20], Hussain et al. [21], Brandstetter et al. [23], Salam et al. [24], Salmeron et al. [25], Leela and Dash [26], Hacil et al. [29], Selvajyothi and Janakiraman [33]. In all the studies discussed in Table 2, the outcomes were compared by selfadopted hypothesis of the authors, which really makes a challenging task for a novel researcher to understand the best techniques of minimizing harmonics in power electronics.

\subsection{Less Novel Work}

From Table 2, it can be seen that the majority of the work are slight enhancement of each other with a slight change in system variables and experimental test bed. Some of the studies e.g. Poorvi et al. [15], Leela and Dash [26], Prusty [32], Gowtami et al. [37] are just the minor amended version of priorly published studies in similar problems. The extent of novelty in this field is very few. However, few studies like Salam et al. [24] and Hacil et al. [29] were found with significant novelty and such studies were found with less repetition. We strongly believe that enhancing somebodies else work is always a novel idea, but it is better if the implemented enhanced model show some significant improvement. Majority of the work was found to enhance total harmonic distortion minimization in the mean range of $3 \%$ by slight change of research variables. If the extent of novelty is minimal, it becomes quite challenging task for the readers to get motivated for investigation in this field.

\subsection{Repetitive Implementation Scenario}

In the area of power electronics, it is always a good idea to test the model in real-time environment for better realization of its outcomes. Table 2 shows that the majority of the studies towards harmonic suppression is carried out in real-time and less in the simulation environment. Some of the studies were also found to combinely use for real-time and simulation study. We strongly agree that a real-time implementation is effective if the researchers showcase their observational outcomes by performing an extensive hardware based experiments. The commercial market has various types of hardware units for distribution of electricity which is not necessary to always match with the laboratory prototypes. Moreover, it was seen that till date there is no mathematical model (other than frequently used Simulink tool or some other proprietary tool) ever used for optimizing power quality in the electrical system. We strongly believe that a mathematical modeling can greatly formulate the problems and can render better solution compared to real-time and simulationbased model.

\section{CONCLUSION}

This paper has review some of the most potential techniques found in the literature that adopts mainly active power filters for significant suppression of harmonics in electrical devices. The paper has discussed the outcomes of various techniques and has presented a state-of-art comparative analysis (Table 1 and Table 2) of the existing review and implementation techniques in a similar field. It can be inferred that the study towards active power filter have not seen much novelty and can be still said to be in the infancy stage of development. Our future work direction will be to develop a model that can fill up the research gap discussed in this paper with an aid of mathematical modelling as well as effective benchmarking. This phase of the study will present a novel mathematical model to generate a proposed predictive control scheme, including the design procedure. The proposed mathematical model will comprise of multiple types of power generation units as well as different types of loads. The study will also consider power generation use of ac/ac and dc/ac with static pulse width modulated converters for voltage conversion and battery banks for long-term energy storage. This part of the study focus on real-time implementation and validating the proposed mathematical model for harmonic suppression using active power filter. The proposed system will formulate a novel technique for active power filter using FPGA for accelerating the controller's performance.

\section{REFERENCES}

[1] Bretschneider, F., Weille, J.R.De.2006. Introduction to Electrophysiological Methods and Instrumentation. Academic Press, Medical, pp. 266

[2] http://worldwidescience.org/topicpages/v/variablespeed+fan+performance.html

[3] Baggini, A.2008. Handbook of Power Quality. John Wiley \& Sons, Technology \& Engineering, pp. 642

[4] http://www.hersheyenergy.com/harmonics.html 
[5] Won, P.K.2001. A Review of Active Power Filters. R\&D Center, Poscon

[6] Chaturvedi, K., Mahor, A., Dwivedi, A. D.2012. Active Power Filter Techniques for Harmonics Suppression in Non Linear Loads. International Journal of Scientific Engineering and Technology. Vol. 1, No. 2, pp. 123-127

[7] Jacob, A., Abraham, B. T, Prakash, N., Philip, R.2014. A Review of Active Power Filters In Power System Applications. International Journal of Advanced Research in Electrical, Electronics and Instrumentation Engineering, Vol. 3, Issue. 6

[8] Raouf, M.H., Nowbakht, A., Haddadi, M.B., Tabatabaei, M.R.2014. A Review of Control Schemes for Active Power Filters in Order to Power Quality Improvement. International Journal of Electrical, Robotics, Electronics and Communications Engineering, Vol.8, No.5

[9] Ahmad, A., Jaglan, P.2014. Compensation of Source Current Harmonics Using Shunt Active Filters. SSRG International Journal of Electrical and Electronics Engineering (SSRG-IJEEE), Vol.1, Issue. 5

[10] Choudhary, A., and Gaur, P.2014. Current Control Strategies for Active Filter for Harmonic Mitigation. International Journal of Innovation and Scientific Research, Vol. 10, No. 1, pp. 27-34

[11] Arthy, G.,.Marimuthu, C.N.2014. Review of Digital control schemes for Active Power Filters.IOSR Journal of Electronics \& Communication Engineering, ISSN: 22781684, pp. 53-62

[12] Afonso, J., Aredes, M., Watanabe, E., Martins, J.2000. Shunt active filter for power quality improvement. Electricity for a Sustainable Urban Development, pp. 683691

[13] Kumar, D.P.2007. Investigations on shunt active power filter for power quality improvement. Department of Electrical Engineering National Institute of Technology Rourkela

[14] Martinek, R, Manas, J., Zidek, J., and Bilik, P.2013. Power Quality Improvement by Shunt Active Performance Filters Emulated by Artificial Intelligence Techniques. In 2nd International Conference on Advances in Computer Science and Engineering, Atlantis

[15] Poorvi, M.S., Parmar, M., Makwana, M.V.2013Harmonic Analysis using Shunt Active Filter", Journal of Information, Knowledge and Research in Electrical Engineering, Vol. 2, Issue. 2, 2013

[16] Daniel, E. S., Abirami, G.2013. Selective Harmonic Elimination using Shunt Hybrid Active Power Filters Operating at Different Switching Frequencies. International Electrical Engineering Journal (IEEJ). Vol. 4, No. 1, pp. 971-977

[17] Martins, A.P.2003. The use of an active power filter for harmonic elimination and power quality improvement in a nonlinear loaded electrical installation. In Proceedings of the International Conference on Renewable Energies and Power Quality, Vol. 3, pp. 1-6

[18] Moran, L.A., Dixon, J.W., and Wallace, R. R.1995. A three-phase active power filter operating with fixed switching frequency for reactive power and current harmonic compensation.Industrial Electronics, IEEE Transactions, Vol. 42, No. 4, pp.402-408

[19] Moran, L., Pastorini, I., Dixon, J., and Wallace, R.2000. Series active power filter compensates current harmonics and voltage unbalance simultaneously. IEE ProceedingsGeneration, Transmission and Distribution, Vol. 147, No. 1 , pp. 31-36

[20] Pacis, M.C., Martinez, J..M., and Tecson, J.V.2010. Modelling and Simulation of Active Power Filters for Harmonic Compensation, Voltage Sags and Swells Mitigation and Power Factor Correction. Proceedings of the World Congress on Engineering and Computer Science, Vol II

[21] Hussain, S., Satyanarayana, K., and Prasad, B. K. V.2011. Power Quality Improvement by Using Active Power Filters. International Journal of Engineering Science and Advanced Technology, Vol.1, Issue.1, pp. 1-7

[22] Ravindra, G., Ramesh, P., and Devaraju, T.2012. Enhancement of Power Quality Using Active Power Filters. International Journal of Scientific and Research Publications, Vol. 2, Issue. 5

[23] Brandstetter, P., Chlebis, P., and Simonik, P.2010. Control Algorithms of Active Power Filters. In Electromagnetics Research Symposium Proceedings, Cambridge, USA

[24] Salam, Z., Cheng, T. P., and Jusoh, A.2008. A Hybrid Active Power Filter Connected to a Photovoltaic Array. Journal - The Institution of Engineers, Malaysia, Vol. 69, No. 1

[25] Salmerón, P., Litrán, S. P., Herrera, R.S., Vázquez, J. R.2010. A Practical Comparative Evaluation of Different Active Harmonic Filter Topologies. International Conference on Renewable Energies and Power Quality

[26] Leela, S., Dash, S.S.2014. High Performance Seven Level Active Shunt filter for Harmonic Mitigation. Journal of Theoretical and Applied Information Technology, Vol. 66, No. 1

[27] Normanyo, E. 2012. Mitigation of Harmonics in a ThreePhase, Four-Wire Distribution System using a System of Shunt Passive Filters. International Journal of Engineering and Technology. Vol. 2 No. 5

[28] Routimo, M.2008. Developing a voltage-source shunt active power filter for improving power quality. Tampere University of Technology

[29] Hacil, M., Khezzar, A., Louze, L., and Nemmour, A. L.2009. Power generation and active filtering of harmonic currents using a new synchronous generator for wind power applications. In Electrical and Electronics Engineering, International Conference, pp. I-206

[30] Madhavi, G., Munisankar, A., Devaraju, T.2014. Mitigation of Power Quality Disturbances using Discrete Wavelet Transforms and Active Power Filters. Proceedings of Second IRF International Conference

[31] Merabet, L., Saad, S., Abdeslam, D.O., and Omeiri, A.2013. A comparative study of harmonic currents extraction by simulation and implementation. International Journal of Electrical Power \& Energy Systems, Vol.53, pp.507-514 
[32] Prusty, S.R.2011. FPGA Based Active Power Filter for Harmonics Mitigation. PhD diss., National Institute of Technology Rourkela

[33] Selvajyothi, K., and Janakiraman, P.A.2010. FPGA-based software implementation of series harmonic compensation for single phase inverters. Hindawi Publishing Corporation VLSI Design. pp. 14

[34] Darly, S.S., Ranjan, P.V., Rabi, B.J.2011. FPGA based Series Active Filter for Power Quality Enhancement. International Electrical Engineering Journal (IEEJ), Vol. 1, No. 1, pp. 506-513

[35] Du, Z., Tolbert, L.M. and Chiasson, J.N.2006. Active harmonic elimination for multilevel converters. Power Electronics, IEEE Transactions. Vol. 21, No. 2, pp. 459469

[36] Xiao, Z., Chen, Y., Deng, X.2013. A Shunt Active Power Filter with Enhanced Dynamic Performance using DualRepetitive Controller and Predictive Compensation. International Journal of Power Electronics and Drive System (IJPEDS), Vol. 3, No. 2, pp. 209-217

[37] Gowtami, D., Ravindra, S., Kalavathi, S.S.2012. Implementation of ANN Based Controllers to Improve the Dynamic Performance of a Shunt Active Power Filter. International Journal of Modern Engineering Research (IJMER), Vol. 2, Issue.4, pp. 2352-2357

[38] Bitoleanu, A., and Popescu, M.2013. The pq theory and Compensating Current Calculation for Shunt Active Power
Filters: Theoretical Aspects and Practical Implementation. Przegląd Elektrotechniczny, Vol. 89

[39] Watanabe, E.H., Aredes, M., and Akagi, H.2004. The pq theory for active filter control: some problems and solutions", Sba: Controle \& Automação Sociedade Brasileira de Automatica, Vol. 15, No. 1, pp. 78-84

[40] Jeevananthan, K.S.2014. Designing of Single Phase Shunt Active Filter Using Instantaneous Power Theory. International Journal of Electrical and Electronics Research, ISSN 2348-6988 (online), Vol. 2, Issue 2, pp.110

[41] Pavlanin, R., Marinelli, M., Zigmund, B.2011. Different View on PQ Theory Used in the Control Algorithm of Active Power Filters. Advances in Electrical and Electronic Engineering, Vol. 5, No. 1-2, pp. 55-60

[42] http://www.synopsys.com/Systems/Saber/Pages/default.asp

[43] Nakamura, S., Iwasa, M., and Nakahara, M.2011. Newton's method for fast speed MPPT of solar panel. In 9th Annual International Energy Conversion Engineering Conference AIAA, Vol. 5654

[44] Couto, E.F., Martins, J. S., Afonso, J. L.2003. Simulation results of a shunt active power filter with control based on pq theory. International Conference on Renewable Energies and Power Quality ,pp. 394 